\title{
CONTROL OF APHIDS IN WHEAT (North Island)
}

\author{
L. W. BLACKMORE \\ Research Division, Department of Agriculture, \\ Palmerston North
}

Summary

Results are given for seven separate trials carried out over the past two seasons in the Rangitikei, Manawatu, Masterton and Hawke's Bay districts. Poor control of aphids (Rhopalosiphum padi L.) was obtained from the use of disulfoton. While moderate but doubtfully economic yield increases were obtained by spraying with demetonS-methyl at $3 \mathrm{oz}$ a.i. per acre during the growth of the crop the greatest increases resulted from the use of a combination of disulfoton at $16 \mathrm{oz}$ a.i. per acre with the seed followed by spraying with demeton-S-methyl. Because of the high cost of this latter treatment, further trials are being planned to see if the rate of disulfoton can be reduced.

\section{INTRODUCTION}

Climatic conditions in the North Island (at least in the moister cropping regions) appear to be very suitable for aphid survival and therefore the annual recurrence of BYDV disease. There is little doubt that the higher spring rainfall and better incidence make plants attractive to the aphid for a longer period, while the comparatively moist summers and mild winters ensure good survival over these periods.

The investigations described in this paper were carried out over the 1965-6 and 1966-7 seasons. Because stem rust did not occur during these seasons, a unique opportunity presented itself for studying aphid control in wheat and its effect on yields.

Experiments over the past two seasons have confirmed the result obtained by A. K. Booth in the 1963-4 season. Spraying with demetonS-methyl gave an average increase of 6.4 bushels per acre over control in a variety by spraying trial in the Marton district.

In all trials described in this paper, disulfoton and demeton-S-methyl are expressed in ounces of active ingredient (a.i.) per acre, while disulfoton is in the form of $5 \%$ a.i. granules.

\section{DISULFOTON WITH THE SEED COMPARED WITH APPLICATION AT EARLY CROP ESTABLISHMENT}

In the 1965-6 season, four trials were laid down comparing disulfoton at 4,8 and $16 \mathrm{oz}$ applied with the seed and also during early crop establishment. Treatments were as follows:

(1) Disulfoton with the seed at $4 \mathrm{oz}$.

(2) Disulfoton with the seed at $8 \mathrm{oz}$.

(3) Disulfoton with the seed at $16 \mathrm{oz}$.

(4) Disulfoton broadcast at early establishment at $4 \mathrm{oz}$.

(5) Disulfoton broadcast at early establishment at $8 \mathrm{oz}$.

(6) Disulfoton broadcast at early establishment at $16 \mathrm{oz}$.

(7) Control. 
Table 1 gives the percentage reductions in aphid numbers. Counts were made eight to nine weeks after sowing.

There were no significant differences in yields for Trials 1,2 and 4.

The reduction in aphid numbers where disulfoton was sown with the seed was $46 \%$ (average for all three rates) compared with $24 \%$ where it was broadcast during early establishment.

\section{Results}

(1) Disulfoton applied with the seed was twice as effective in killing aphids as it was when broadcast during early establishment.

(2) While the percentages of aphids killed were variable, there were no obvious differences in the percentage killed by the three rates of disulfoton.

(3) Disulfoton was apparently not effective for a long enough period in the plant to influence yields except for the $16 \mathrm{oz}$ rate in Trial 3 (see Table 1), but even here the increases $(5.4 \mathrm{bu} /$ acre for placement with the seed and $4.2 \mathrm{bu} /$ acre for broadcasting during early establishment), although significant, were comparatively small and proved to be uneconomic. It appears that the effectiveness of disulfoton sown with the seed tends to disappear with the onset of the extension stages of growth in the plant.

(4) Where disulfoton was broadcast during early establishment, its effective aphid-killing period was shorter than where an equivalent amount was sown with the seed.

\section{DISULFOTON APPLIED AT EARLY ESTABLISHMENT COMPARED WITH SPRAYING WITH DEMETON-S-METHYL}

In a trial conducted in the 1965-6 season, demeton-S-methyl $3 \mathrm{oz}$ and disulfoton at $16 \mathrm{oz}$, were applied to the growing crop at two different times of application. Single applications were applied at two different times (time $\mathrm{A}$ and time $\mathrm{B}$ ) and these were compared with double applications (times A plus B). Treatments were as follows:

(1) Demeton-S-methyl applied time A (8/10/65) (Feeke's Scale 2 to 3).

(2) Demeton-S-methyl applied time B $(15 / 10 / 65)$ (Feeke's Scale 7).

(3) Demeton-S-methyl applied times A plus B.

(4) Disulfoton applied time A (8/10/65) .

(5) Disulfoton applied time B $(15 / 10 / 65)$

(6) Disulfoton applied times A plus B.

(7) Control.

Results:

(1) Spraying with demeton-S-methyl (Feeke's Scale $=2$ to 3), while reducing aphid numbers, proved to be too early and had no significant effect on yield.

(2) Spraying at time B (Feeke's Scale 7) resulted in a substantial reduction in aphid numbers and in a small but highly significant increase in yield.

(3) Spraying at times A plus B was not superior to B alone. 


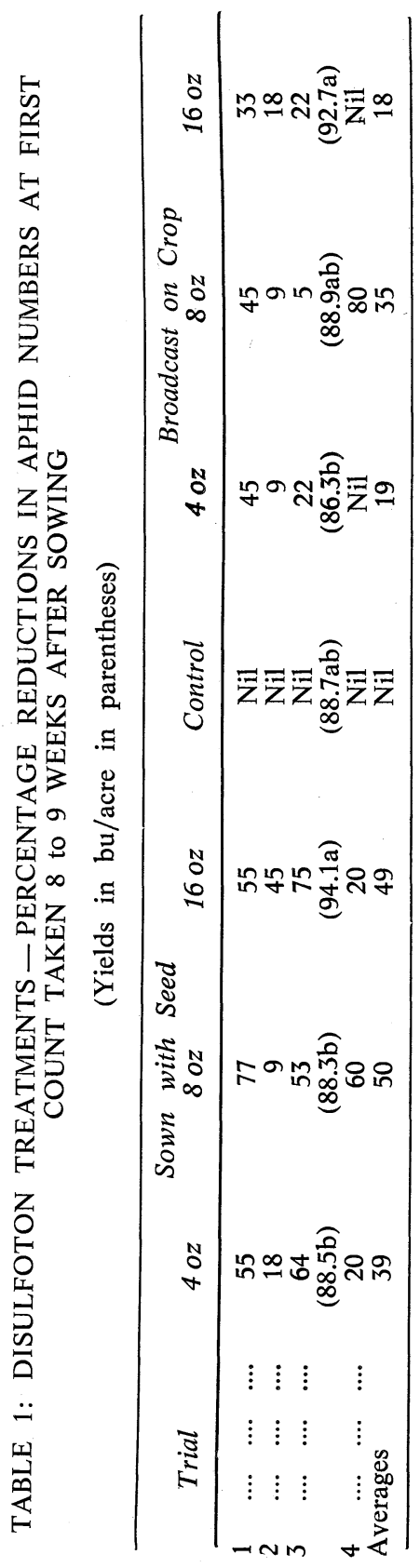

238 
(4) Disulfoton applied at time $\mathrm{A}$; and time $\mathrm{B}$; and times $\mathrm{A}$ plus $\mathrm{B}$; resulted in no increases in yields. Aphid numbers were, however, substantially reduced for time B applications.

\section{DISULFOTON WITH THE SEED AND THREE TIMES OF SPRAYING WITH DEMETON-S-METHYL}

Two trials were conducted in the 1966-7 season in which three times of spraying (using $3 \mathrm{oz}$ demeton-S-methyl) and disulfoton $16 \mathrm{oz}$ were compared in all combinations giving sixteen treatments as follows:

(1) Control

(2) Spraying time A

(3) Spraying time B

(4) Spraying times $A+B$

(5) Spraying time $\mathrm{C}$

(6) Spraying times $\mathrm{A}+\mathrm{C}$

(7) Spraying times $B+C$

(8) Spraying times $\mathrm{A}+\mathrm{B}+\mathrm{C}$

(9) Granules (G) with the seed

(10) Granules + spraying time A
(11) Granules + spraying time B

(12) Granules + spraying time $\mathrm{A}+\mathrm{B}$

(13) Granules + spraying time C

(14) Granules + spraying times $\mathrm{A}+\mathrm{C}$

(15) Granules + spraying times $\mathrm{B}+\mathrm{C}$

(16) Granules + spraying times $\mathrm{A}+\mathrm{B}+\mathrm{C}$

\section{Aphid Counts}

These were taken immediately before and three days after each spraying. The technique used was to collect 10 clumps ( 3 to 4 plants) at random from each plot, excluding the outside rows. These clumps were removed with a trowel and placed separately into plastic bags for counting, which was done by the Seed Testing staff. The number of clumps per plot with one or more aphids was recorded. The aphid counts for each trial together with BYDV symptoms, percentage of "blackheads" and yields, are set out in Tables 2 and 3.

\section{Aphid Flights}

In order to determine the period of aphid flights and the relationship between these flights and crop infestation, an aphid trap was placed in the centre of each trial.

Trial (1): C. A. W. Cockburn, Onepuhi:

$$
\text { Aphid Flights }
$$

The first aphid flights occurred approximately 20 days after crop emer gence and terminated 21 days later.

\section{Degree of Aphid Infestation}

Aphid infestation in this crop was relatively low at all stages of growth. The number of aphid-infested clumps in "control" (out of a total of 10 per plot) ranged from 1.0 at Feeke's Scale 5 to a maximum of 4.5 at Feeke's Scale 8 to 9. Aphid infestation in this crop would probably pass unnoticed except to a trained observer.

\section{Results}

Effects of Disulfoton and Demeton-S-methyl on Aphid Numbers

Spraying resulted in a clear pattern of effects on aphid numbers. These were reduced for disulfoton and for times A plus B spraying 


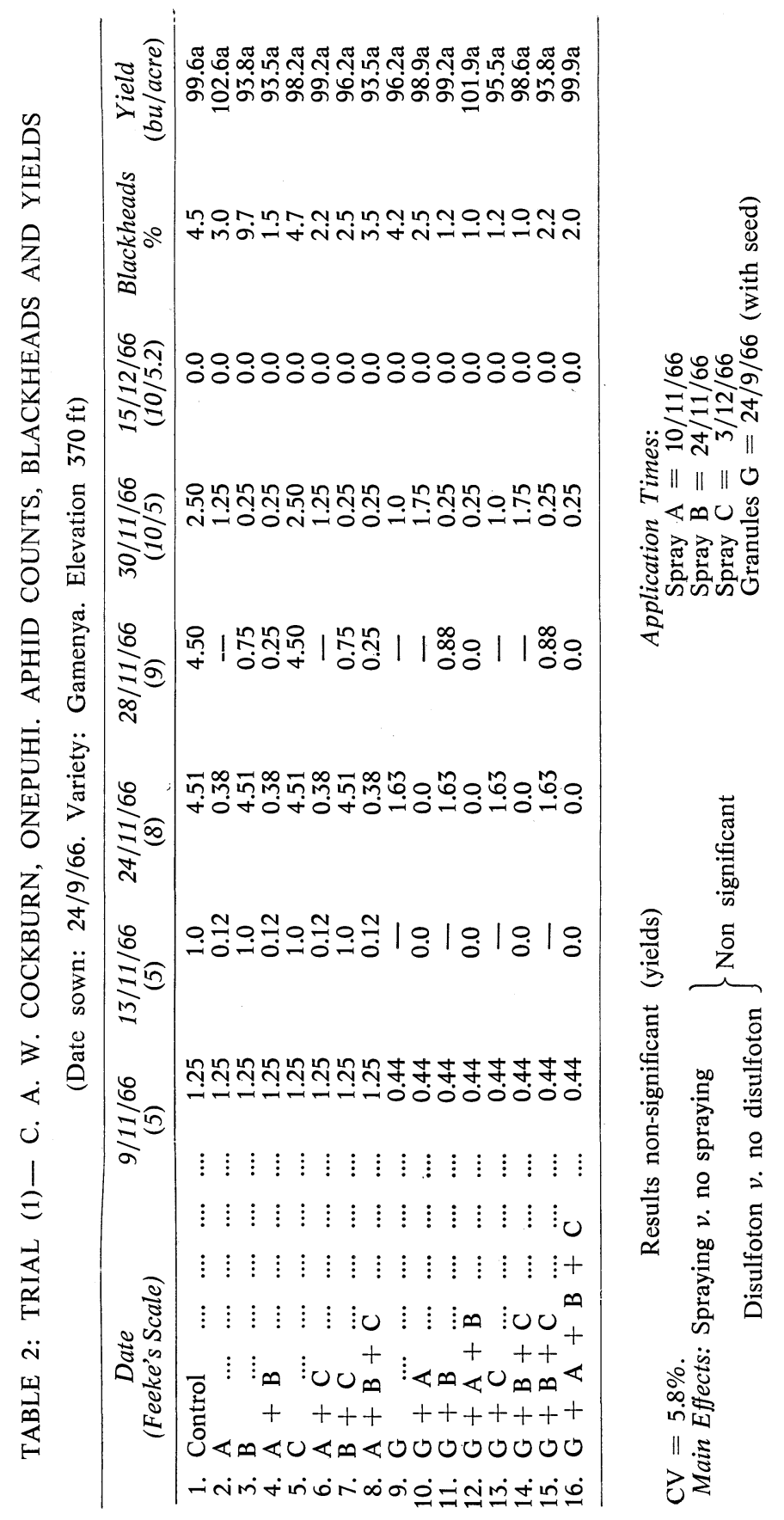

240 
but not for time $\mathrm{C}$ which appears to have been too late. Treatments 12 $(\mathrm{G}+\mathrm{A}+\mathrm{B})$ and $16(\mathrm{G}+\mathrm{A}+\mathrm{B}+\mathrm{C})$ reduced numbers to a very low level (averaged 0.14 infected clumps in 10). It should be noted that "G" stands for disulfoton granules.

Relationship between Aphid Numbers, Blackheads and Yields

The amount of BYDV symptoms was very low. No visual differences could be distinguished between treatments except that there was a tendency for the early infection centres to spread more in the absence of disulfoton.

The pattern of aphid control has not been clearly reflected in the relative percentages of blackheads or in yields for the different treatments. The main effects were:

(1) The percentage of blackheads was comparatively low (averaged less than $3 \%$ for all treatments), as would be expected with a low incidence of aphids.

(2) The percentage of blackheads for all treatments including disulfoton (Treatments 9-16 inclusive) was less than half that for the "no disulfoton" treatments $(1.9 \%$ compared with $4.0 \%)$ and yet there were no significant differences in yield. This suggests that compensatory influences must operate during the growth of the crop.

(3) There were no significant differences in yield for any of the treatments. Neither were there any differences in yield for the main effects - i.e., "spraying" versus "n"ot spraying" and "disulfoton" versus "no disulfoton".

Results from this trial clearly indicate that, with the low aphid infestation of the order experienced in this trial, it would be uneconomic to spray.

\section{Effect of Organophosphates on Crop Performance}

As there were no significant differences in yield between treatments, it can be concluded that the application of $16 \mathrm{oz}$ disulfoton plus three sprayings with $3 \mathrm{oz}$ demeton-S-methyl did not affect crop performances.

Trial (2): A. M. Bisley \& Co., Palmerston North

\section{Aphid Flights}

The first aphid flights virtually coincided with the emergence of the crop. This was approximately 17 days earlier than for Trial (1).

\section{Degree of Aphid Infestation}

There was little difference in aphid infestation between the two trials in the early stages but the build-up in numbers in this trial was much more rapid and remained at a higher level for a longer period. This extended period of activity was obviously important. The number of aphid-infested clumps out of ten ranged from 0.56 at Feeke's Scale 5, to 8.5 at Feeke's Scale 7. Aphid infestation in this crop (on a careful inspection) would not have been difficult to detect by most people. 


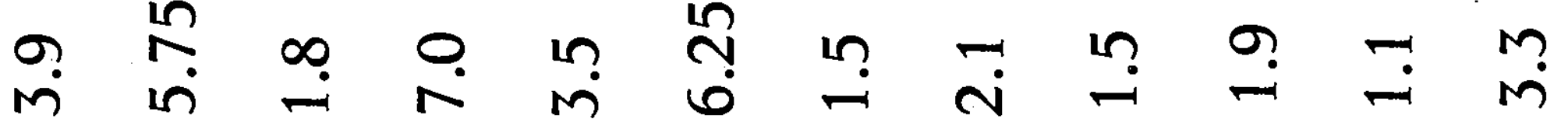

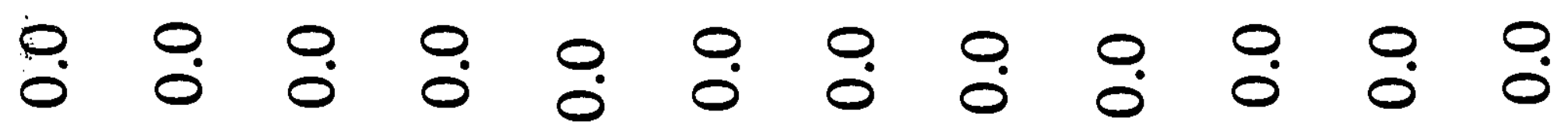

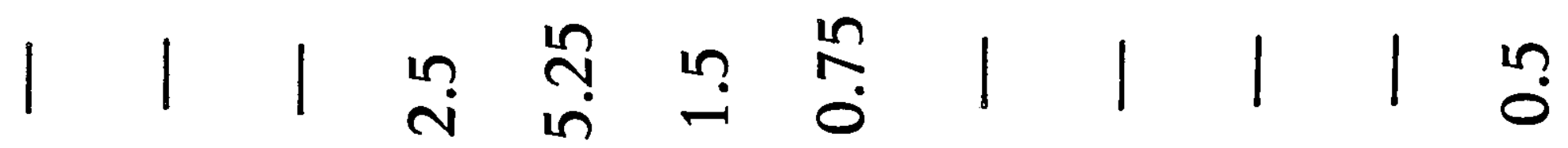

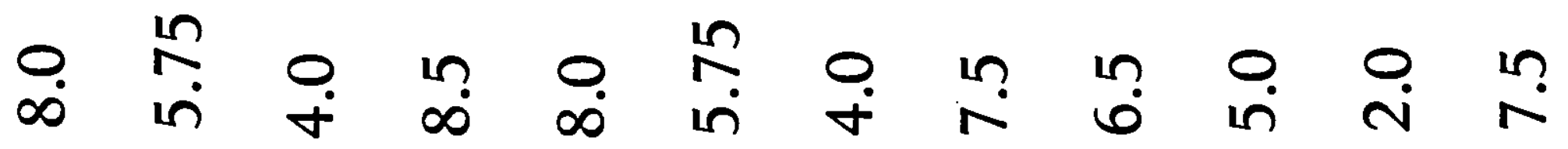

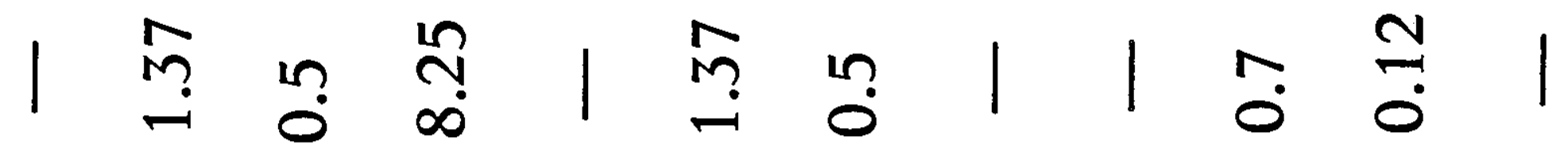

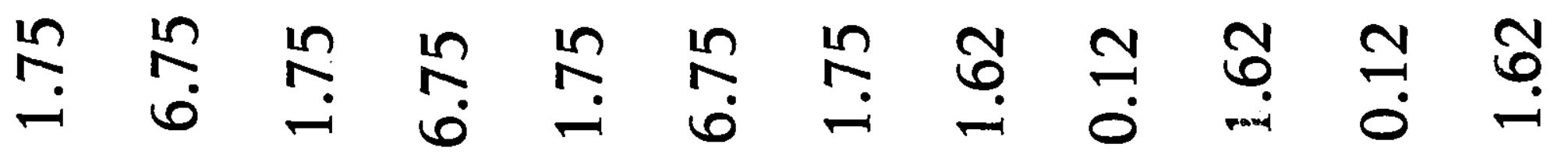

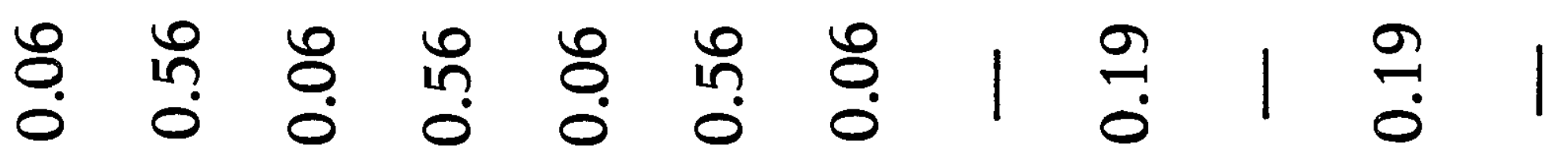

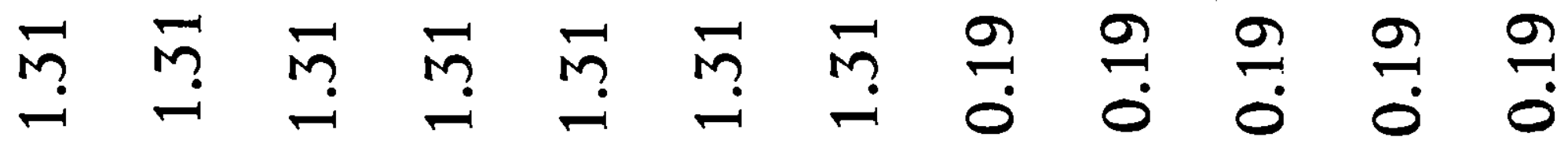




\section{Results}

\section{Effects of Disulfoton and Demeton-S-methyl on Aphid Numbers}

All three spray treatments and granules separately reduced aphid numbers. Two, three and four factor interactions tended to be strongly additive in their effects. However, this was not necessarily reflected in yield increases as will be shown later. (See Tables 2 and 3 showing the effects of disulfoton and demeton-S-methyl on aphid numbers.)

Disulfoton granules on their own were effective in controlling aphids for approximately only five weeks. They did, however, have an important contributary effect when followed by spraying with demeton-S-methyl.

\section{Relationship between BYDV Symptoms, Blackheads and Yields}

There appears to be a close relationship between the percentages of BYDV, blackheads, and yields. Yields tended to be affected when the percentage of blackheads reached the $5 \%$ to $10 \%$ level. Below these levels compensatory influences during crop growth apparently operated.

\section{Effects of Organophosphates on Yields}

While as separate treatments disulfoton granules and spraying at times $\mathrm{A}, \mathrm{B}$, and $\mathrm{C}$ all gave increased yields, only $\mathrm{B}$ reached significance. However, as main effects, disulfoton at all times of spraying has given significant yield increases at the $1 \%$ level. This indicates that control at all times is important and stresses the need for a systemic insecticide persistent enough to maintain its lethal effect throughout the critical stages of growth. Unfortunately, both this trial and Trial (1) clearly demonstrate that neither disulfoton nor demeton-S-methyl is sufficiently persistent in spring-sown wheat for this to be achieved.

The two-factor interactions involving demeton-S-methyl were negative for yields. The factors were times of spraying " $A+B$ " and " $B+C$ ". On the other hand, the two-factor interactions involving disulfoton (i.e., $\mathrm{A}+\mathrm{G}$; $B+G$; and $C+G$ ) were in the main additive in their effects on yield. The greatest two-factor additive effect was for disulfoton plus spraying with demeton-S-methyl at time C. The additive effects for the three- and four-factor interactions were more pronounced.

\section{Negative Effects of Two-factor Demeton-S-methyl Interactions}

At first sight, it is difficult to understand why the two-factor demeton-Smethyl interactions were negative and not additive in their effects on yield.

Trials with insects deal with an important "number $\times$ time" relationship which makes "timing" of extreme importance in determining the effectiveness of control measures. It follows that there is an optimum time (in any particular set of circumstances) at which to apply a single spray to obtain the maximum response.

If, then, a spray is applied at this optimum time (which is basically associated with the numbers present), the employment of an additional time: of spraying is unlikely to be additive in its effect. In other words, the sum of the two separate effects of these sprayings is unlikely to exceed that for the optimum spraying - that is, the responses are likely to be complementary rather than additive in their effects. 


\section{Contributory Effect of Disulfoton}

It is clear from a study of yield data that the use of disulfoton along with one or more applications of demeton-S-methyl has resulted in distinct increases in yields. The average increase of 3.9 bushels per acre is significant at the $1 \%$ level. There has been a corresponding decrease in BYDV symptoms as well as the percentage of blackheads. This is set out in Table 4.

TABLE 4: EFFECTS OF DISULFOTON ON YIELDS AND INCIDENCE OF BYDV AND BLACKHEADS

\begin{tabular}{lcccc}
\hline Treatment & Av. \% BYDV & Av. $\begin{array}{c}\% \text { Black- } \\
\text { heads }\end{array}$ & $\begin{array}{c}\text { Av. Yields } \\
\text { (bu/acre) }\end{array}$ \\
\hline $\begin{array}{l}1 \text { to } 8 \text { incl. } \\
\text { (no disulfoton) }\end{array}$ & $\ldots$. & 4.8 & 11.5 & $59.6 \mathrm{bB}$ \\
$\begin{array}{l}9 \text { to } 16 \text { incl. } \\
\text { (disulfoton) }\end{array}$ & $\ldots$. & 1.6 & 7.6 & $63.5 \mathrm{aA}$ \\
\hline
\end{tabular}

These effects must be due to the protection by disulfoton against aphids up to the five weeks stage. This again stresses the importance of obtaining good control at all times. It also shows that relatively low aphid numbers during early establishment may contribute substantially in reducing overall yields. It is interesting to note that the increase in yields due to the use yields. It is interesting to note that the increase in yelds duted about $33 \%$ of the yield increase obtained from the best treatments-i.e., 3.9 bu compared with $11.9 \mathrm{bu} /$ acre increase.

The fact that disulfoton's influence is operating before spraying begins explains why the two-factor interactions involving disulfoton are in the main additive.

As has previously been shown, disulfoton on its own cannot be relied on to give an increase in yield. Its use may, however, create a potential for increased yield. This may be realized, however, only if there is a follow-up with demeton-S-methyl spray - that is, any beneficial control in aphids up to 5 to 8 weeks may be largely lost if conditions subsequently are favourable for a large population increase.

In both trials where aphid traps were used, the effects of disulfoton sown with the seed had disappeared before the aphid flights had finished. This in itself allowed a nucleus of aphids for a subsequent build-up.

\section{PROSPECTS FOR CONTROL}

\section{SPRAYING WITH DEMETON-S-METHYL}

In Trial (2) a significant 6 bu increase was obtained from time B spraying which was applied after aphid flights had ceased and when the degree of aphid infestation was comparatively high (6.75 infected clumps out of 10). Its chief value was that it prevented a dangerous build-up of aphids from occurring again that season. The profit from this single spraying would be about $\$ 6.00$ per acre. This was obviously not a maximum yield increase because the best disulfoton plus demeton-S-methyl treatments gave increases of nearly $12 \mathrm{bu} /$ acre, or approximately double. It should further be pointed out that this latter increase was in all probability not the true maximum increase judged by the percentage of blackheads $(8.4 \%)$. In the trials conducted over the past two seasons, the variety 
Gamenya averaged just over $4.2 \mathrm{bu} / \mathrm{acre}$ increase for two sprayings. On the other hand, the increased yields from Aotea and Hilgendorf ' 61 were 6.6 and $8.2 \mathrm{bu} /$ acre, respectively. It can be concluded that spraying is doubtfully economic for Gamenya but may be economic for varieties less resistant to BYDV such as Aotea, Hilgendorf, Tripple Dirk and Raven. However, this would need to be substantiated by further trial work.

\section{Disulfoton}

While this material, when sown with the seed at $4 \mathrm{oz}, 8 \mathrm{oz}$ and $16 \mathrm{oz}$, has substantially reduced aphid numbers up to eight weeks after drilling, its influence on yields when used on its own has been very disappoinung. In fact, significant increases in yield were obtained in only one trial. This was a $5 \mathrm{bu}$ increase which, however, did not cover the cost of the treatment. This is unfortunate, as the use of a chemical with the seed has much to recommend it from a farmer's point of view. What is required is a more persistent material which is sufficiently lasting to give good protection against aphids during the susceptible stages of growth.

\section{Disulfoton + Demeton-S-METHYL}

In Trial (2) disulfoton at $16 \mathrm{oz}$ with the seed followed by spraying with $3 \mathrm{oz}$ of demeton-S-methyl applied at time $\mathrm{C}$ gave the substantial increase of $11.8 \mathrm{bu} /$ acre compared with a $6 \mathrm{bu}$ increase for the best single spray treatment with demeton-S-methyl. However, because of the comparatively high cost of this treatment $(\$ 14.50$ per acre $)$ the return $(\$ 5.50$ per acre) was rather lower than might be expected. The main point to keep in mind here is that a material like disulfoton used with the seed can only be regarded as an insurance - that is, in the presence of harmful numbers of aphids, this chemical creates a potential for increased yield. This potential can be fully realized, however, only if there is a follow-up with demeton-S-methyl spray. If the rate of disulfoton sown with the seed could be reduced, this method could well be economic. Trials have already established that $4 \mathrm{oz}$ and $8 \mathrm{oz}$ rates of disulfoton have substantially reduced aphid numbers up to eight weeks after sowing, so there is some justification for this approach.

It is intended to check on reluced rates of disulfoton in this coming season's trials. It appears that the important point at issue is not so much the rate of disulfoton used (although this has yet to be substantiated) as the lack of persistence of the material in the wheat plant under spring sown conditions.

\section{Aphid Problem in Relation to Different Districts or Regions}

It is most likely that aphid activity varies considerably from region to region, or even from district to district. For this reason, it is important to establish when flights begin, how long they last, and their intensity. The length of the breeding season on their new hosts should also be recorded, as well as data on prevailing winds, elevation and temperature ranges.

Such data are likely to be of considerable importance in determining where and when control measures are warranted. For instance, in some districts control measures may seldom be necessary; in others they may be necessary in some seasons; and in others control may be required
each season. 


\section{CONCLLŨSIONS}

(1) Trial work to date indicates that BYDV disease is of considerable economic importance in most North Island wheat-growing districts.

(2) The present investigation has given a clearer understanding of the factors involved in the control of this disease.

(3) Both chemicals used were effective in killing aphids. While disulfoton has proved to be much more persistent than demeton-S-methyl, it is not persistent enough to control aphids beyond the eighth week in spring sown wheat.

(4) Low infestations of aphids, although influencing the number of blackheads present, do not appear to affect yields owing to compensatory influences during growth. It is probable there is a progressive reduction in the plant's ability to compensate for this disease with increasing maturity.

Unforiunately it is difficult to predict from an inspection of a wheat crop at any particular time whether the aphids present will produce harmful numbers in the immediate future, as this is so dependent on the weather that follows. This suggests that a "protective" rather than a "corrective" approach would be best.

What is needed is a reasonably priced chemical that can be sown with the seed and is persistent enough to give full protection throughout the susceptible period of growth. Such a chemical would no doubt be difficult to produce because of the dilution factor associated with the extensive stages of growth in the wheat plant.

\section{ACKNOWLEDGEMENTS}

Thanks are due to B. E. and J. G. Manson and E. O'Brien for their valuable assistance and suggestions in the conduct of these trials, the staff of the Seed Testing Station, Palmerston North, for making the aphid counts, and to the Superintendent, Biometrics Section, for statistical analyses. 